\title{
Defluidization Investigation into Bubbling Fluidized Bed Particles with Alkaline Addition during Pyrolysis
}

\author{
Zuldian PRIMA ${ }^{1 *}$ and Reiji NODA ${ }^{1}$ \\ ${ }^{1}$ Division of Environmental Engineering Science, Gunma University, 1 Chome-5-1 Tenjincho, Kiryu, Gunma 376-8515, Japan
}

\begin{abstract}
Some unwanted inorganic materials, such as alkaline compounds contained in biomass, have the potential to create slagging formations with oxide compounds from either inside or outside the bubbling fluidized bed (BFB). The process involved 88-125 $\mu \mathrm{m}$ silica sand and clay (bentonite) as bed particles during pyrolysis with $\mathrm{KCl}$ addition at $700^{\circ} \mathrm{C}$ to represent biomass under superficial$\mathrm{N}_{2}$-velocity operation. Agglomeration formation was confirmed by the decrease in the average $\Delta P$ of the experiment, which theoretically should take place during the addition of $\mathrm{KCl}$, while the defluidization condition was confirmed by a consistent average $\triangle \mathrm{P}$ particle deviation, even after further $\mathrm{KCl}$ additions. Investigation of 0.005 and $1 \mathrm{~g}$ encapsulated $\mathrm{KCl}$ periodical addition showed that the silica sand has a tendency to form agglomeration faster than bentonite, specifically after $0.0211 \mathrm{~g}$ of $\mathrm{KCl}$ addition $(0.0032 \%$ of total silica sand mass). Meanwhile, the bentonite has a tendency to achieve defluidization formation more easily than silica sand according to deviation analysis. The ability of silica sand to maintain fluidization longer than bentonite indicates that silica sand is the better particle for this process.
\end{abstract}

\section{Introduction}

Increasing the efficiency of biomass energy production by utilizing proper thermal conversion processes to achieve good product quality can save energy and increase the use of cleaner energy. The bubbling fluidized bed (BFB) pyrolysis process is a technique which involves the efficient combustion of raw materials at high temperatures via particle circulation supported by $\mathrm{N}_{2}$ flow in the superficial velocity condition. Particle fluidization ensures that thermal conversion is run optimally during the process. Therefore, the size, type, and flowrate velocity of particles in circulation have a significant effect on the completion of the reaction.

Silica sand particles already have numerous applications in fluidization. This work will consider the competitiveness of another particle with similar properties. The use of clay with a high silica content should reduce the likeliness of particle degradation, even in hightemperature conditions. However, it is possible that defluidization phenomena will take place during the reaction, causing a decrease in the efficiency of the process. The increase in particle size likely occurs during thermal processing due to the agglomeration formation in the bed particles. It is affected by the presence of some alkaline compounds contained inside raw biomass, such as $\mathrm{K}$, which easily associates with some oxide compounds to increase the particle size until the particle fluidization stops. Therefore, defluidization analysis becomes important when comparing silica sand and clay (bentonite) during BFB pyrolysis and will be observed in detail in this work.

\section{Method}

\subsection{Particle circulation preparation}

Both silica sand and bentonite particle mixtures were dominated by oxide compounds, contained particles of heterogenous sizes, and were provided by Japanese companies. The densities of silica sand and thermal bentonite were estimated to be 2 and $2.9 \mathrm{~g} / \mathrm{cm}^{3}$, respectively, which places them in Group A according to the Geldard Classification (Kunii and Levenspiel, 1991). Sieving and milling were carried out by a mechanical sieve and mortar to obtain homogenous particle sizes of $88-125 \mu \mathrm{m}$. Particles were placed into the BFB chamber, which has a vertical height of $500 \mathrm{~mm}$ and an inner diameter (ID) of $43 \mathrm{~mm}$, before start-up. The total initial bed particle mass was around $65 \mathrm{~g}$, and it was located 30 $\mathrm{mm}$ above the $50 \mu \mathrm{m}$ porous distributor plate at the bottom of the chamber. The particle size was selected to prevent back pressure and ensure fluidization could take place after achieving the minimum fluidization velocity $\left(\mathrm{U}_{\mathrm{mf}}\right)$ of $\mathrm{N}_{2}$. Therefore, the $\mathrm{U}_{\mathrm{mf}}$ had to be determined both at room temperature $\left(24^{\circ} \mathrm{C}\right.$ for silica sand and $19^{\circ} \mathrm{C}$ for bentonite) and pyrolysis temperature $\left(700^{\circ} \mathrm{C}\right)$. Figures 1 and 2 show the $\mathrm{U}_{\mathrm{mf}}$ analysis for silica sand and bentonite.

\footnotetext{
*Corresponding author: t172c603@gunma-u.ac.jp
} 


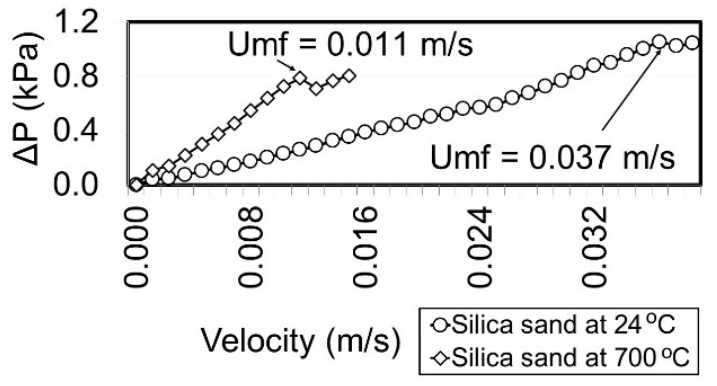

Figure 1. The $\mathrm{U}_{\mathrm{mf}}$ analysis of silica sand at $24^{\circ} \mathrm{C}$ (room temperature) and $700^{\circ} \mathrm{C}$ (pyrolysis temperature)

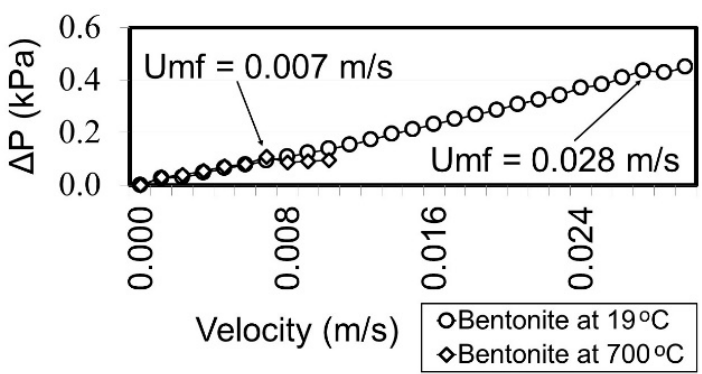

Figure 2. $\mathrm{U}_{\mathrm{mf}}$ analysis of bentonite at $19^{\circ} \mathrm{C}$ (room temperature) and $700^{\circ} \mathrm{C}$ (pyrolysis temperature)

The ratio between room and pyrolysis temperatures in Figure 2 indicates that the $\mathrm{U}_{\mathrm{mf}}$ value is 3-4 times higher at the pyrolysis temperature for bentonite. The $\mathrm{U}_{\mathrm{mf}}$ estimation was considered when setting the $\mathrm{N}_{2}$ velocity to approximately $0.012 \mathrm{~m} / \mathrm{s}$, or 2 litres per minute $(\mathrm{L} / \mathrm{min})$, to create a superficial velocity condition at $700^{\circ} \mathrm{C}$.

Bentonite has a high moisture content, which evaporates during heating and fluidization of the particles, thereby decreasing the particle mass. The presence of water implies that flocculation easily occurs and decreases the capability to form chemical bonds with other bed particles. This also relates to its capability to swell up to several times its initial size in atmospheric conditions (Basnayaka et al., 2018). Therefore, thermal pre-treatment was needed to ensure its readiness for use in the pyrolysis process.

\subsection{Raw material preparation}

The raw material was biomass containing a rich supply of organic compounds, which are easily reacted and released from the chamber at $700^{\circ} \mathrm{C}$. However, some biochar would remain inside the BFB chamber due to its inorganic components, which would mix with the fluidized particles. $\mathrm{KCl}$ is used to represent the inorganic compounds found in biomass. The $88-125 \mu \mathrm{m} \mathrm{KCl}$ was obtained by grinding powder to obtain the same particle size as the bed particles. After that, it was placed into commercial capsules of various sizes so that $0.005 \mathrm{~g}$ and $1 \mathrm{~g}$ of $\mathrm{KCl}$ could be added at $15 \mathrm{~min}$ intervals. The use of an empty capsule made it easier to input $\mathrm{KCl}$ into the $\mathrm{BFB}$ chamber as shown in Figure 3. The empty capsule mass was approximately $0.1 \mathrm{~g}$, and it was composed of $89.2 \%$ cellulose, $2 \% \mathrm{TiO}_{2}, 1.3 \% \mathrm{KCl}$ and $1 \%$ other compounds; therefore, it combusted almost perfectly during the process.
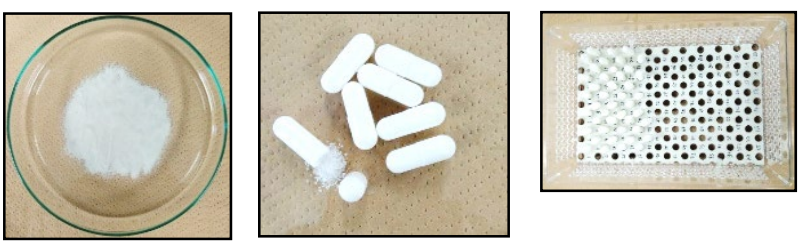

Figure 3. Preparation of encapsulated $\mathrm{KCl}$

\subsection{BFB pyrolysis operation}

BFB pyrolysis was commenced by heating up BFB with an electrical microheater to achieve a temperature of $700^{\circ} \mathrm{C}$. This took approximately $60 \mathrm{~min}$ supported by continuous $\mathrm{N}_{2}$ supply from the distributor section. Three ball valves on the top of the bed acted as nozzles for inputting encapsulated $\mathrm{KCl}$. $\mathrm{KCl}$ was added every $15 \mathrm{~min}$, supported by $\mathrm{N}_{2}$ from the top reactor to avoid backflow. Three pressure probes were introduced into the bottom of the reactor $(\mathrm{P} 1)$, the filter pipeline $(\mathrm{P} 2)$, and the exhaust line $(\mathrm{P} 3)$ to record the pressure difference $(\Delta \mathrm{P})$. A thermocouple was set and placed into the BFB chamber to maintain temperature at $700^{\circ} \mathrm{C}$. Aa packaged sintering filter was installed into the updraft BFB discharge line to catch fine particles before being emitted to the atmosphere.

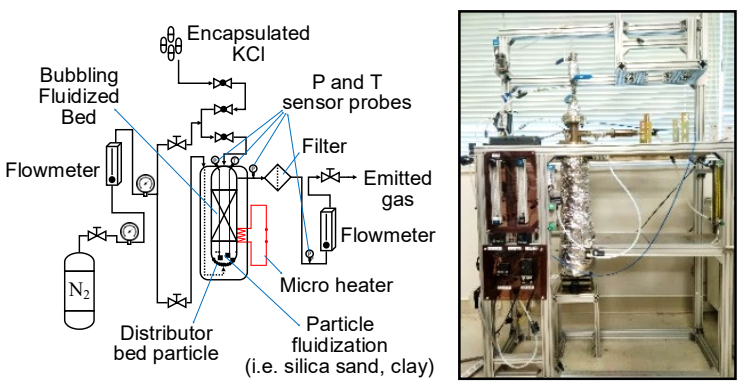

Figure 4. Bubbling fluidized bed (BFB) pyrolysis system

The differences in mass inside the bed reactor and the sintering filter, before and after pyrolysis were calculated to determine the total remaining bed particle masses, amount of elutriation, and the loss mass. A detailed description of the BFB system is provided in Figure 4.

\section{Results}

\subsection{Defluidization analysis of silica sand particles}

Defluidization analysis was carried out based on the pressure drop $(\Delta \mathrm{P})$ during the experiment. To maintain the fluidization condition inside the bed, $\mathrm{KCl}$ was added in 15 min intervals to decrease continuously and getting loss capability. Thermal gravimetric analysis (TGA) of the endothermic reaction at $700^{\circ} \mathrm{C}$ under $\mathrm{N}_{2}$ atmosphere, as shown in Figure 5, confirmed that the silica sand and $\mathrm{KCl}$ were more difficult to degrade than the cellulose capsule 
during pyrolysis. The amount of mass loss was predicted to come from the cellulose capsule degradation, which almost completely volatilized during pyrolysis.

(a)

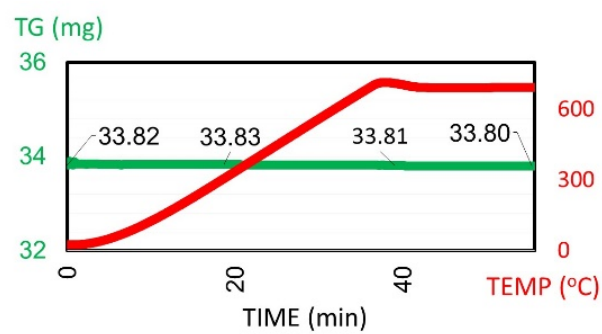

(b)

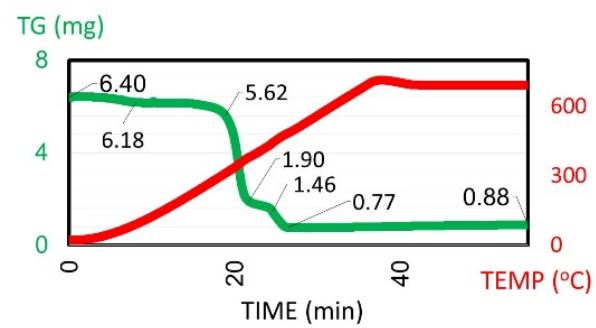

(c)

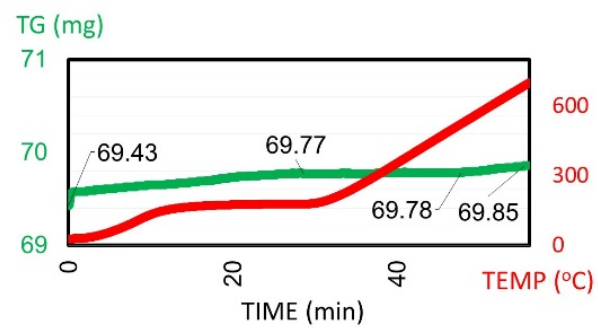

Figure 5. TGA on (a) KCl, (b) Empty capsule, and (c) Silica sand

The average $\Delta \mathrm{P}$ was calculated experimentally to determine the agglomeration and defluidization conditions associated with the change in $\Delta \mathrm{P}$ within an interval of $15 \mathrm{~min}$. The $\Delta \mathrm{P}$ values by theory and elutriation analysis were calculated using Pascal's law, as shown in equations 1 and 2, to confirm the ideal process in which all the particles do not degrade.

$$
\begin{gathered}
\Delta P \text { by theory }=\frac{m_{\text {bed particle }} \times g}{A_{B F B}} \\
\Delta P \text { by elutriation }=\frac{\left(m_{\text {bed particle }}-m_{\text {filter particle }}\right) \times g}{A_{B F B}}
\end{gathered}
$$

Therefore, those $\Delta \mathrm{P}$ values always should to be higher than $\Delta \mathrm{P}$ by experiment.

\subsubsection{Analysis of silica sand with $0.005 \mathrm{~g} \mathrm{KCl}$ added/15 $\mathrm{min}$}

This was the lowest interval analysis to identify the initial agglomeration formation before reaching the defluidization condition. In this step, $\Delta \mathrm{P}$ by experiment increased gradually after initializing the $\mathrm{N}_{2}$ supply and adding several capsules. The particle fluidization slightly decreased $\Delta \mathrm{P}$ although fluidization still occurred until the last $\mathrm{KCl}$ addition, when the total added $\mathrm{KCl}$ was $0.21 \mathrm{~g}$, as seen in Table 1. The initial agglomeration is indicated in Figure 6 by the decrease in particle fluctuation, where the standard deviation decreases from $0.00551 \mathrm{KPa}$ at the initial fluidization to become $0.00349 \mathrm{KPa}$ after several $\mathrm{KCl}$ additions. Analysis of average $\Delta \mathrm{P}$ confirmed that the agglomeration was formed after $0.02 \mathrm{~g}$ of $\mathrm{KCl}$ was added or $0.032 \%$ of the initial bed particle mass. The increase in agglomeration was taking place continuously in accordance with the decrease in average $\Delta \mathrm{P}$ by experiment of $0.497 \%$.

(a)

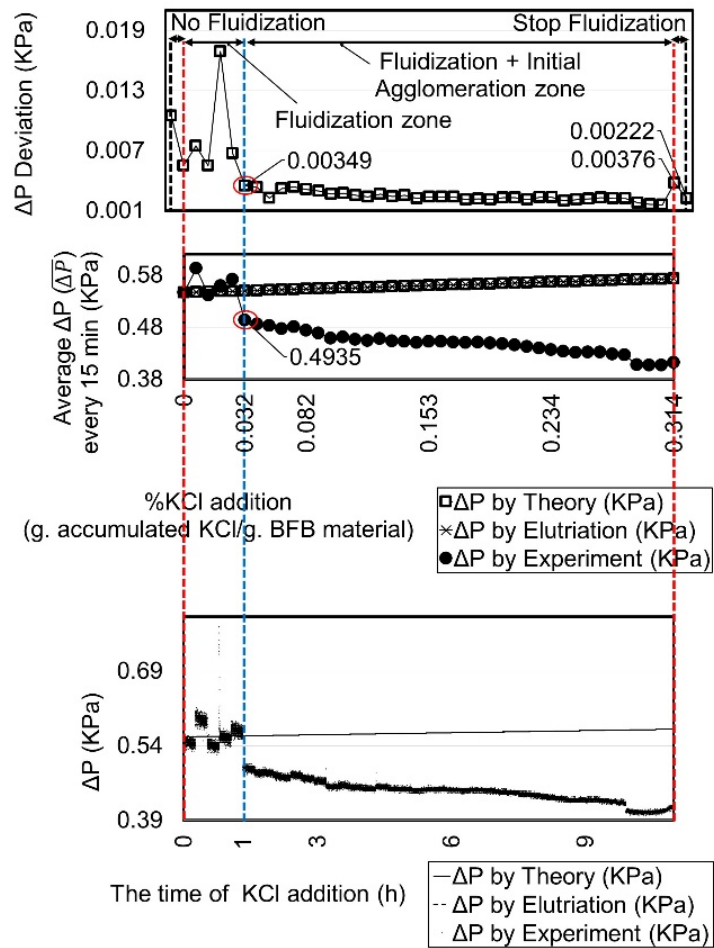

Figure 6. Agglomeration of silica sand with $0.005 \mathrm{~g} \mathrm{KCl}$ added $/ 15$ min against $\Delta \mathrm{P}$ by theory and elutriation movement, based on (a) $\Delta \mathrm{P}$ deviation, (b) Average $\Delta \mathrm{P}$ by experiment, (c) $\Delta \mathrm{P}$ by experiment (raw data)

The agglomeration formation was confirmed by sieving the bed particle after pyrolysis to obtain particles larger than $125 \mu \mathrm{m}(+125 \mu \mathrm{m})$. After sieving, $0.82 \mathrm{~g}$ of agglomerated particles were obtained, as can be seen in Table 1 and Figure 7.

(a)

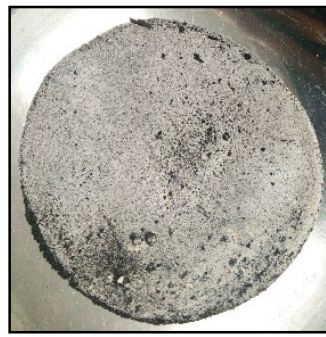

(b)

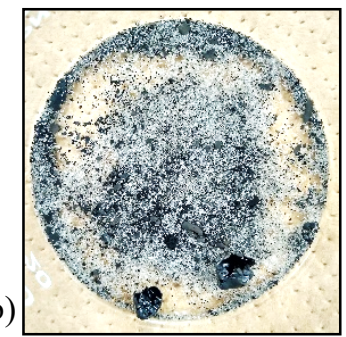

Figure 7. The mixed bed particle (silica sand) after pyrolysis within $0.005 \mathrm{gr} / 15 \mathrm{~min}$ interval $\mathrm{KCl}$ addition (a) Before separation, (b) After separation

The silica sand particles were almost stable. Table 1 shows that the total emitted bed particle mass was $4 \mathrm{~g}$ and the total accumulated filter particle mass was $0.2 \mathrm{~g}$. This 
stable performance resulted in a small mass loss of approximately $3.8 \mathrm{~g}$.

Table 1. Mass loss calculation of silica sand BFB with $0.005 \mathrm{~g}$ $\mathrm{KCl}$ added/15 min (left) and $1 \mathrm{~g} \mathrm{KCl}$ added/15 $\mathrm{min}$ (right)
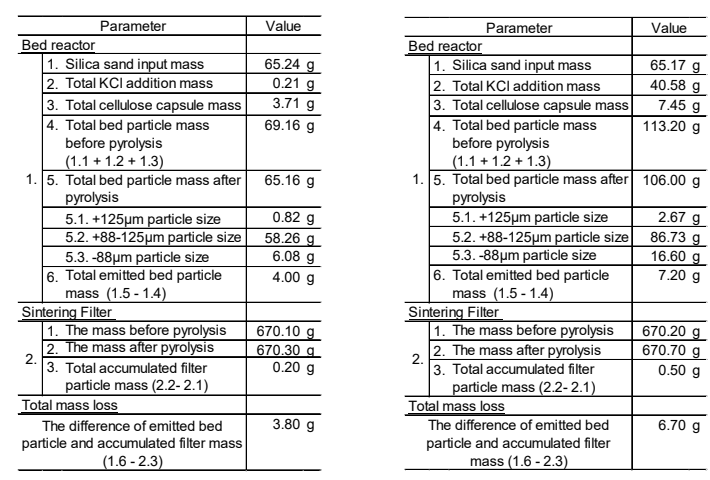

\subsubsection{Analysis of silica sand with $1 \mathrm{~g} \mathrm{KCl}$ added/15 min}

More $\mathrm{KCl}$ was added in the experiment to determine the new defluidization condition, as agglomerations were completely formed with less $\mathrm{KCl}$. It lasted $10 \mathrm{~h}$, or 40 additions of $\mathrm{KCl}$, reaching an added mass of $40.58 \mathrm{~g}$. The defluidization condition was confirmed when the movement of $\Delta \mathrm{P}$ stopped or, when particle movement was stable even with further $\mathrm{KCl}$ addition. The defluidization condition occurs when $\Delta \mathrm{P}$ deviation is stable compared to $\Delta \mathrm{P}$ deviation when the $\mathrm{N}_{2}$ supply is stopped. Before achieving defluidization, $\Delta \mathrm{P}$ changes as the bed particles find more stable formations. In this phase, fine and bed particles react, creating larger particles and incremental changes in $\Delta \mathrm{P}$. On complete defluidization, even $\mathrm{KCl}$ addition does not significantly change the $\Delta \mathrm{P}$ value.

(a)

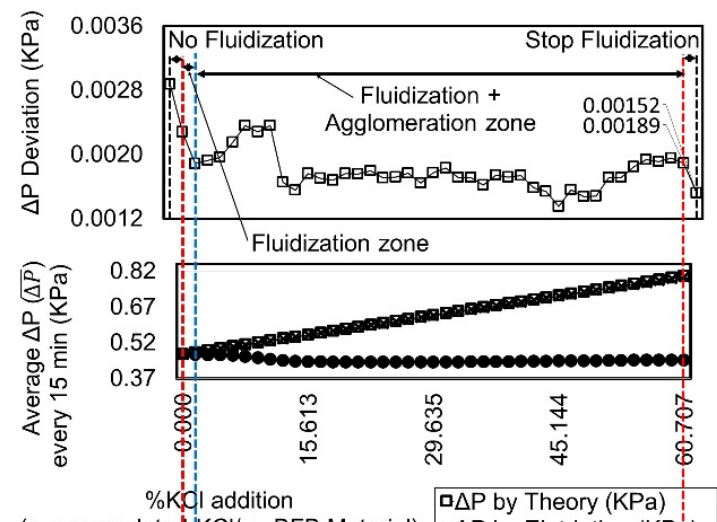

(b)

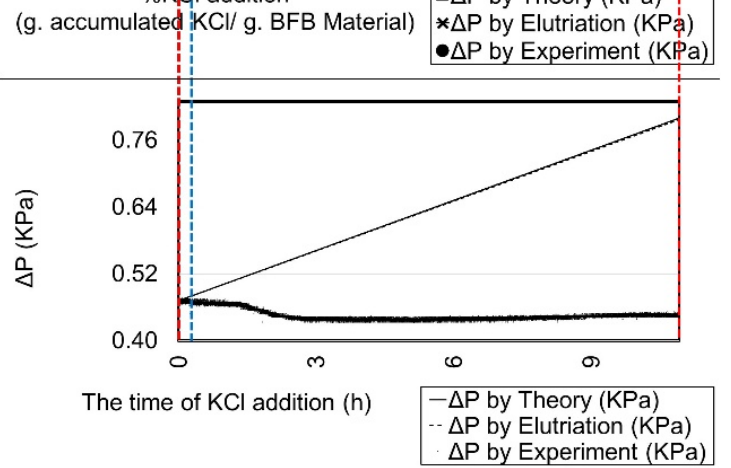

Figure 8. Defluidization investigation of silica sand with $1 \mathrm{~g}$ $\mathrm{KCl}$ added $/ 15$ min against $\Delta \mathrm{P}$ by theory and elutriation movement, based on (a) $\Delta \mathrm{P}$ deviation, (b) Average $\Delta \mathrm{P}$ by experiment, and (c) $\Delta \mathrm{P}$ by experiment (raw data)

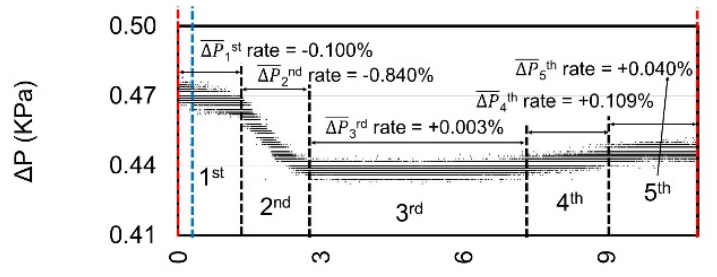

The time of $\mathrm{KCl}$ addition (h)

$\Delta \mathrm{P}$ by Experiment $(\mathrm{KPa})$

Figure 9. Defluidization investigation of silica sand with $1 \mathrm{~g}$ $\mathrm{KCl}$ added $/ 15$ min based on $\%$ average $\Delta \mathrm{P}$ by experiment rate

Figure 8(a), confirms agglomeration formation. Meanwhile, the defluidization condition was not yet achieved after comparing the $\Delta \mathrm{P}$ deviations, which still fluctuated until the last addition of $\mathrm{KCl}$, compared to the $\Delta \mathrm{P}$ condition $\mathrm{N}_{2}$ supply stopped, $0.00189 \mathrm{KPa}$ and $0.00152 \mathrm{KPa}$ respectively. There are five agglomeration areas depicted in Figure 9 according to the change of $\Delta \mathrm{P}$ by experiment rate. The $1^{\text {st }}$ and $2^{\text {nd }}$ areas show the most significant change, where the bed particle vigorously reacts with $\mathrm{KCl}$ to make a large agglomeration. The decreased rate of the $1^{\text {st }}$ and $2^{\text {nd }}$ area was $0.1 \%$ and $0.84 \%$ respectively, with the total added mass of $\mathrm{KCl}$ at the end of the 2 nd area being $10.18 \mathrm{~g}$, or $15.613 \%$ of the initial bed particle mass, as shown in Figure 8(b). Meanwhile, the $3^{\text {rd }}$ area shows the most stable condition with a slightly increased rate of $0.03 \%$, and total added mass of $\mathrm{KCl}$ at $24.37 \mathrm{~g}$ or $37.395 \%$. In this case, only a small amount of agglomeration was formed. The $4^{\text {th }}$ and $5^{\text {th }}$ area confirm a small increment of agglomeration formation with total added mass of $\mathrm{KCl}$ at $33.48 \mathrm{~g}$ or $51.378 \%$ and $39.56 \mathrm{~g}$ or $60.707 \%$, respectively. The stability condition confirmed the rate of change amount at $0.109 \%$ and $0.040 \%$ respectively as well. (a).

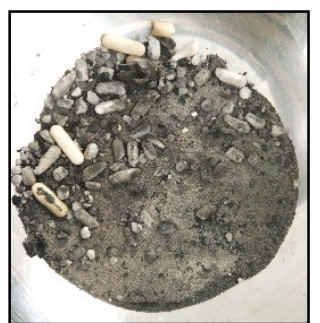

(b)

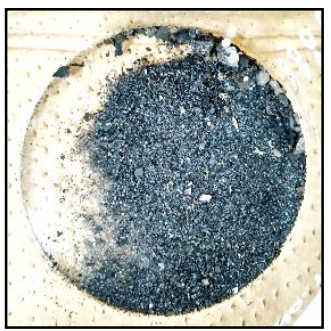

Figure 10. Mixed silica sand and $\mathrm{KCl}$ particles after pyrolysis within $1 \mathrm{~g} \mathrm{KCl}$ added/15 min interval reaction (a) Before, and (b) After the sieving process

Agglomeration was proved by the presence of a higher bed particle size after pyrolysis, as can be seen in Figure 10. The mass balance in Table 1 confirmed that there was $2.67 \mathrm{~g}$ of agglomerated particles obtained from the sieving process. That agglomeration has a weak structure which was very easy to break down with vibration during sieving. Sintering of the agglomeration is relevant as higher 
temperatures would increase agglomeration (Kunii and Levenspiel, 1991). The mass loss was confirmed to be 6.7 g.

\subsection{Defluidization analysis of bentonite particles}

Bentonite was selected to be used as another bed particle. It has the potential to be considered as a support catalyst to increase reaction efficiency. However, according to TGA, not only was the empty capsule but degrading, but also approximately $10.9 \%$ of the bentonite as shown in Figure 11. The high degradation rate increases the disparity between $\Delta \mathrm{P}$ by experiment and $\Delta \mathrm{P}$ by theory and elutriation.

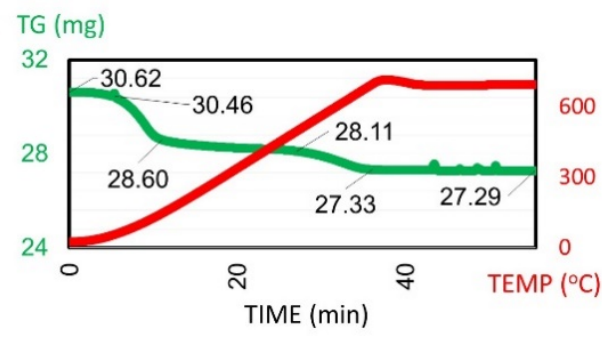

Figure 11. TG analysis on clay (bentonite)

\subsubsection{Analysis bentonite with $0.005 \mathrm{~g} \mathrm{KCl}$ added/15 $\min$}

The identification of agglomeration in this case was carried out by adding a total of $0.3 \mathrm{~g} \mathrm{KCl}$. Using a similar method to the silica sand, agglomeration formation was shown with $\triangle \mathrm{P}$ deviation $0.03461 \mathrm{KPa}$ as shown in Figure 12(a). It was achieved after $0.09 \mathrm{~g}$ of $\mathrm{KCl}$ was added or $0.14 \%$ of the initial bed particle mass as shown in Figure 12(b).

(a).

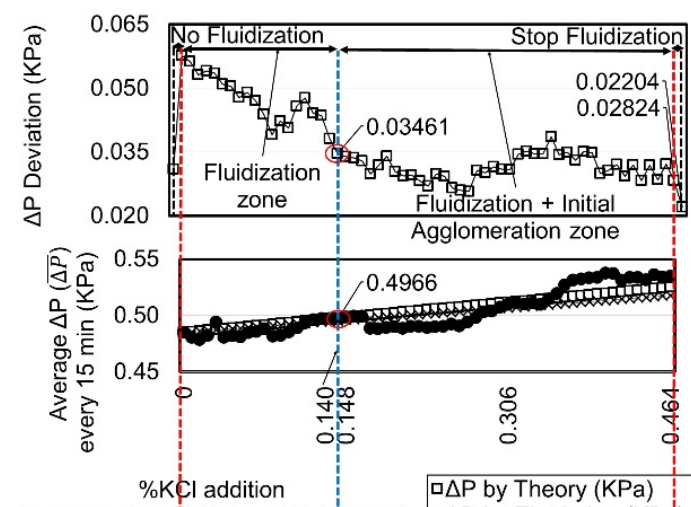

(b).

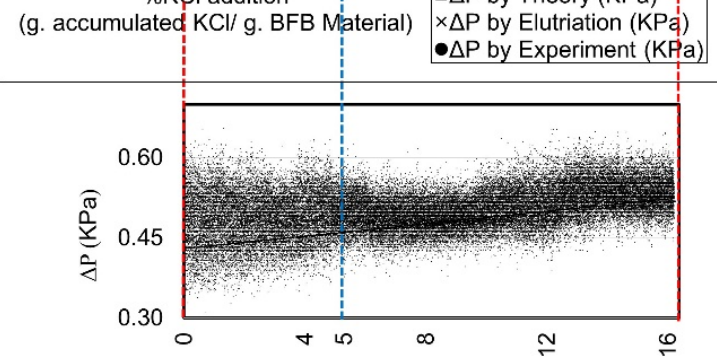

(c).

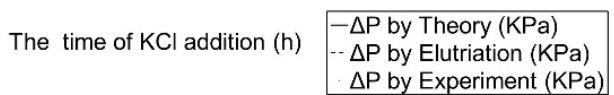

Figure 12. $\Delta \mathrm{P}$ by experiment values based on (a). Deviation data, (b). Average data and (c). Raw data against $\Delta \mathrm{P}$ by theory and elutriation between bentonite and $0.005 \mathrm{~g} \mathrm{KCl}$ added/15 min.

The analysis shows that the bentonite takes longer to form an agglomeration than silica sand. The degradation of bentonite changes its structure, meaning ions inside the compound will react with some ions supported with its high adsorption capability during the process (Petrovic et al., 2014). The high degradation of bentonite was proved by the $11.81 \mathrm{~g}$ of accumulated fine particles inside the sintering filter, as shown in Table 2.

Table 2. The mass loss calculation of BFB analysis using bentonite with $0.005 \mathrm{~g} \mathrm{KCl}$ added/15 min (left) and $1 \mathrm{~g} \mathrm{KCl}$ added $/ 15 \mathrm{~min}$ (right)
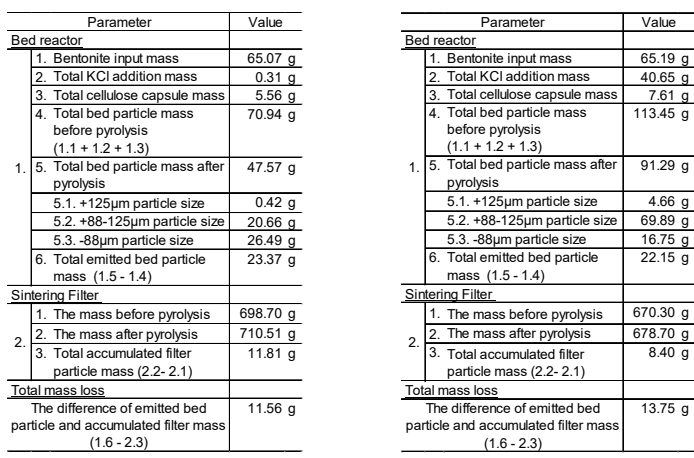

Figure 13 shows some small agglomerations from both before and after the mechanical sieving process. Table 2 confirmed that the total agglomerated particle mass was $0.42 \mathrm{~g}$.

(a).

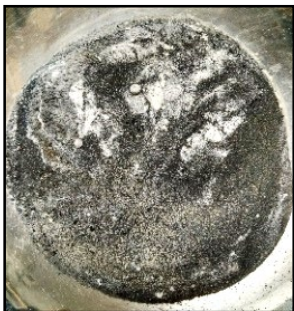

(b).

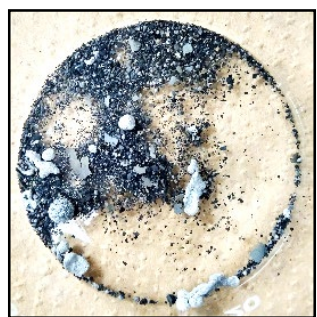

Figure 13. Bentonite after pyrolysis with $0.005 \mathrm{~g} \mathrm{KCl}$ added/15 min (a) Before separation, (b) After separation

\subsubsection{Analysis clay (bentonite) against $1 \mathrm{gr} / 15 \mathrm{~min}$ interval $\mathrm{KCl}$ addition}

The $\Delta \mathrm{P}$ deviation for $10 \mathrm{~h}$ with a total of $40.65 \mathrm{~g} \mathrm{KCl}$ added was compared to the $\Delta \mathrm{P}$ deviation once the after $\mathrm{N}_{2}$ supply stopped. This showed that the initial defluidization condition was achieved when the $\Delta \mathrm{P}$ values were 0.00216 followed by slight change 0.00224 until the last addition compared to $0.00221 \mathrm{KPa}$ respectively as shown in Figure 14(a). Figure 15 confirmed the agglomeration was formed in 4 phases, based on average $\Delta \mathrm{P}$ by experiment rate. The $1^{\text {st }}$ area was the most significant change in agglomeration with $3.05 \mathrm{~g} \mathrm{KCl}$ added or $4.671 \%$ of the initial bed particle mass, the $\Delta \mathrm{P}$ rate decreased by $0.549 \%$ as shown in Figure 14(b). A small agglomeration took place in the 2 nd area with $5.08 \mathrm{~g}$ or $7.796 \%$ of initial bed particle mass. The $3 \mathrm{rd}$ 
area shows the beginning of defluidization, involving continued agglomeration formation with added $\mathrm{KCl}$ of $32.5 \mathrm{~g}$ or $49.855 \%$ of the initial mass. In the $4^{\text {th }}$ area, the defluidization formation continued to stabilization. The experiment was carried out until the last $\mathrm{KCl}$ addition, totalling $40.65 \mathrm{~g}$ or $62.355 \%$ of the initial bed particle mass.

(a)

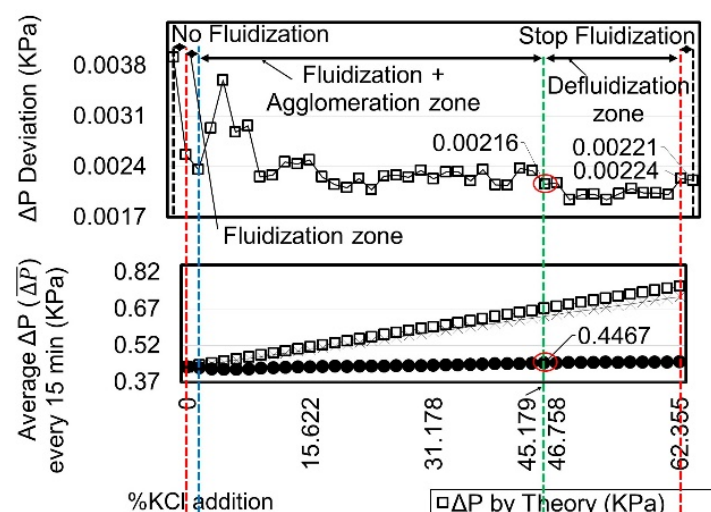

(b)
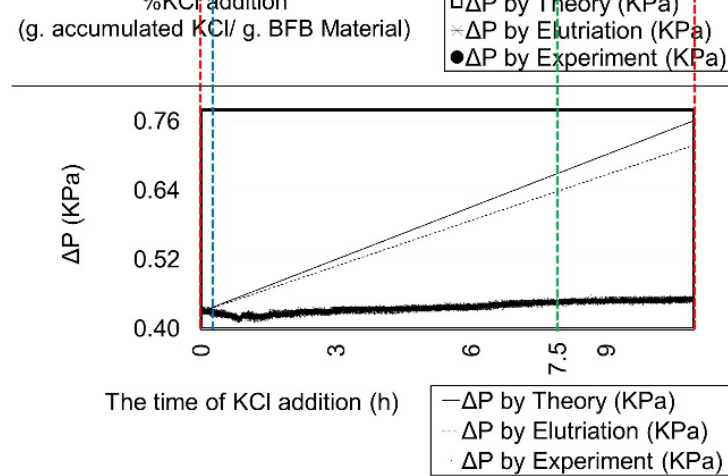

Figure 14. (a). $\Delta \mathrm{P}$ deviation, (b). Average $\Delta \mathrm{P}$ and (c). $\Delta \mathrm{P}$ by experiment (raw data) against $\Delta \mathrm{P}$ by theory and elutriation of bentonite with $1 \mathrm{~g} \mathrm{KCl}$ added/15 min

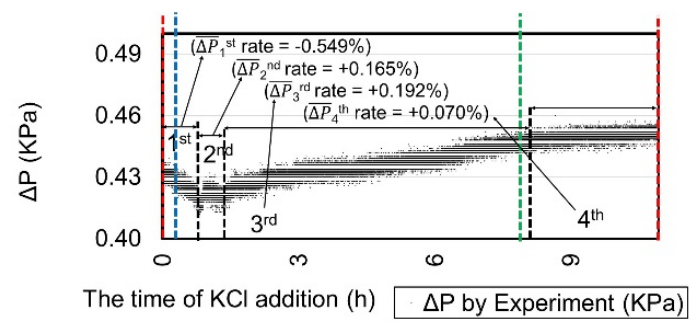

Figure 15. Defluidization investigation of bentonite with $1 \mathrm{~g}$ $\mathrm{KCl}$ added $/ 15$ min based on $\%$ average $\Delta \mathrm{P}$ by experiment rate

The analysis in Table 2 shows that bentonite has a higher potential to emit a large amount of fine particles than silica sand, which will be remained inside the filter. (a).

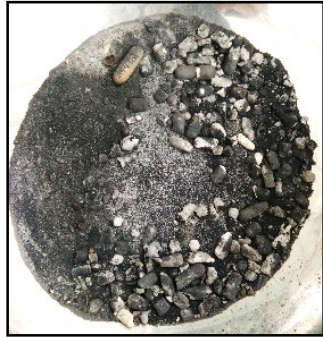

(b)

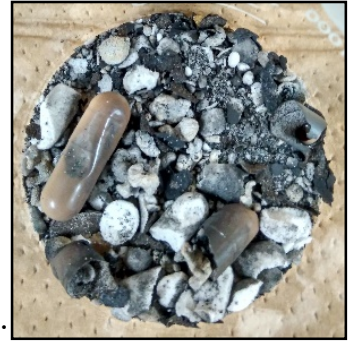

Figure 16. Bentonite and $\mathrm{KCl}$ particles after pyrolysis with $1 \mathrm{~g}$ $\mathrm{KCl}$ added/15 min interval reaction (a). Before, and (b). After the sieving process

The high volume of fine particles causes a lot of agglomeration, as the particles mix easier and have a higher surface area when smaller. After being sieved, the agglomeration size is larger than the initial particles $(+125$ $\mu \mathrm{m})$ with a total mass of $4.66 \mathrm{~g}$ collected, as seen in Table 2 and Figure 16. This shows that the agglomeration was tightly bound with the $\mathrm{KCl}$ even after separation, unlike with the silica sand agglomeration in Figure 10 which broke up due to vibrations during the mechanical sieving process.

\section{Conclusion}

The defluidization condition was preceded by agglomeration formation. Silica sand tends to agglomerate faster than clay bentonite. However, bentonite tends to degrade and reach the defluidization phase first by forming larger, sintered agglomerated particles.

\section{Acknowledgement}

We would like to thank the SATREPS project which fully financially supports this research.

\section{References}

Basnayaka, L., N. Subasinghe, and B. Albijanic; "Influence of Clays on Fine Particle Filtration," Appl. Clay Sci., 156, 45-52 (2018)

Kunii, D and O. Levenspiel; Fluidization Engineering Handbook, pp.75-77, Butterworth-Heinemann, Boston, U.S.A. (1991)

Petrovic, Z., P. Dugic, V. Aleksic, S. Begic, J. Sadadinovic, V. Micic and N. Kljajic; "Composition, Structure and Textural Characteristics of Domestic Acid Activated Bentonite," Contemp. Mater., 1, 133-139 (2014) 